The following are short summaries of each case :

S.s. Faraday. - The wave was visible like a line of high land on the horizon about five minutes before it struck the vessel.

S.s. Westernland.-A huge wave rose to a great height just in advance of the ship. No other similar waves were met with. About noon the wind had changed from S.W. to W.N.W.

S.s. Germanic.-Wind W.N.W. with terrific squalls. Shipped a tremendous sea over bow.

S.s. Umbria.-The disturbance came from, $\mathrm{N}$. W. and consisted of two waves. The first one was broken, the second one green. The wind had previously changed from S.W. to N.W.

H.M.S. Orontes. - While steaming in smooth water a huge wave broke over the vessel forward.

S. Festina Lente. - A steep sea fell on board from both sides.

S.s. Manhattan. The sea was high, but fairly true until a mountainous wave broke on board from N.W.

S.s. Diamond.-Lying to, awaiting daylight to enter port. The wave was heard some time before it was seen, and then seemed to be about 40 feet high. The vessel never rose to it, but was literally submerged for a time.

An examination of the chart will show that with the exception of the Westernland each wave may have originated at a common centre, and might therefore be due to subaqueous volcanic activity. However, as the solitary waves which strike the west coast of South America and the so-called Death Waves on the west coast of Ireland are said to be regarded as pre cursors of storms, it is possible that these solitary Atlantic waves may be due to a similar cause; but even then it is inexplicable how a number of comparatively small and regular waves can be converted into one abnormal one, or how the reported changes of wind and consequent confused sea could produce such a wave. It will be noticed that the dates for the Festina Lente, Manhattan, and Diamond are very close together, and therefore there is a possibility that they were struck by the same wave.

Glasgow, February 18.

\section{The Presence of a Stridulating Organ in a Spider.}

WHILsT spending a short time at Alice Springs, in Centra Australia, during the course of last year, in connection with the Horn Scientific Expedition, I found that it was firmly believed by a considerable number of people, white men and natives alike, that a spider existed in Central Australia which made booming noise at night. Thanks to the assistance of the blacks, the spider itself was easily captured, but I could detect no organ capable of producing a booming sound. The animal forms a tubular burrow, about three-quarters of, or an inch, in diameter which passes down for some eighteen to twenty-four inches in a slightly slanting direction until it terminates in a smal chamber capable of holding the animal comfortably. In this chamber are found fragments of beetles upon which the animal has preyed, and a certain amount of web material ; but there is no regular lining to the tube or chamber. The spider, which may reach a length of two and a half inches, and a span across the legs of five inches, proves to be Phrictis crassipes, belonging to the tribe Territelaria, to which also belongs the wellknown Mygale.

After listening carefully for the noise, and spending with a friend a night out in the open, in a spot where the booming could be heard, we came to the conclusion that the noise attributed to the spider was, in reality, made by a quail.

However, we kept some dozen specimens under observation in tin and wooden boxes, and after a few days in captivity, during which time they were very sluggish, one or two of them began to be more active, and on irritating one of the livelier ones (a large female) with a straw, I was pleased to see her rise on her hinder legs, and to hear her make a low whistling noise, moving alternately the palps up and down on the cheliceræ as she did so. Whilst doing this she would make short angry darts at the straw.

On examination it was seen that the surface of the basal joint of the palp was provided with a somewhat oval-shaped comb-like structure composed of hard chitinous rods of various lengths, each ending in a club-shaped head. The comb is so placed that when the palp is moved up and down it rubs against a special part of the chelicera, which is provided with several rows of strong, sharply-tapering spines, and the sound produced can be heard, when the spider is in a box in a quiet room, at a distance of, at any rate, six or eight feet.

I was not at the time aware of the fact that, in the Transactions of the Entomological Society for $1877, \mathrm{Mr}$. Wood Mason had described a very similar stridulating organ in another groundspider, Mygale stridulans, and it is interesting to note the close resemblance between, as well as the presence of, the organs in these two genera, both of which belong to the tribe Territelaria. The figure given by Mr. Wood Mason admirably illustrates the position of the spider when it stridulates.

I hope to publish a full description of the organ in the volume dealing with the work of the Horn Expedition.

Biological Laboratory, Melbourne Univ January 24.

\section{The Spectrum Top.}

PERHAPS some of your readers may be glad to learn that the curious phenomena of the spectrum top can be shown on a screen to a large audience. It is only necessary to paint the usual black lines and sector on a suitable disc of glass, and then to mount it in a revolving stage which can be rotated in a lantern by means of a multiplying wheel. The projected disc of light must not be too large ; if the lime-light be used the disc may be about 2 feet in diameter, and about double that size with the electric arc. A great variety of effects can be obtained by interposing coloured glasses in the path of the beam; e.g. with a green glass, and in diffused gas-light, the dark sector and lines appear to be mauve-coloured when suddenly stopped after rapid rotation, or when very slowly rotated, but become of a dark blue when the gas is turned off. On rotating the disc in the usual way the lines appear to be blue, green, and violet.

With a blue glass in gas-light the dark sector and lines appear to be yellow when suddenly stopped, but a fine purple without diffused light. The colours given by the lines at a moderate rate of rotation are red, grey, green, and biue. With a monochromatic red glass, the lines appear to be blue, grey, red, and dark red.

Is it not somewhat extraordinary that a rich blue colour can be obtained when dealing only with monochromatic red light ? With whatever coloured light the disc is fed, the characteristic red lines at the centre, and blue at the periphery, or vice versa, seem almost invariably to appear. Altogether the phenomenon is wortby of further study by physiologists and physicists; the lantern appears to throw, in a double sense, new light upon this interesting problem. The idea of employing transmitted instead of reflected light for producing the phenomena of the spectrum top is partly the suggestion of Mr. T. J. Walls, instrument maker, Edinburgh, who constructed the disc for me.

Edinburgh, March 4. DAWSON TURNER.

\section{THE AGE OF THE EARTH.}

PROF. PERRY and I had not to wait long after the publication of his article " On the Age of the Earth" (NATURE, January 3,1895 , pp. 224-227) to learn that there was no ground for the assumption of greater conductivity of rock at higher temperatures, on which his effort to find that the consolidation of the earth took place far earlier than 400 million years ago, is chiefly founded. In a letter of date January 13, most courteously written to me by Dr. Robert $\mathrm{W}^{\prime}$ eber in consequence of his having seen by my letter to Prof. Perry of December 13, that we were anxious to find how far his experimental results regarding differences of thermal conductivity and specific heat at different temperatures could be accepted as trustworthy, he tells me that he had made farther experiments on an improved plan, and that on the whole his investigations do not seem to prove augmentation of conductivity with temperature; and he kindly gives me, with permission to communicate to NATURE, the following results, hitherto unpublished, of experiments which he made in $\mathrm{t}$ e years $\mathrm{I} 885$ and $\mathrm{I} 886$ 